\title{
CELEBRATING URBAN WATER, NATURE AND ECOLOGICAL PROCESSES TO MITIGATE URBAN RISK
}

\author{
MUKHERJEE MAHUA \\ Department of Architecture and Planning, IIT Roorkee, India
}

\begin{abstract}
Water historically facilitated cities to survive, sustain, celebrate and create distinguished identities. This can offer livelihood, wisdom, culture, entertainment, sensibility, and most importantly nature connect, be it river, lake, pond, stream or fountain. Diminishing qualitative and quantitative presence of water bring rising crisis and risks to cities in the recent period. This paper explores whether, in addition to multiple eco system services (ESS), urban water can provide urban risk mitigation while celebrating nature connect and natural ecological processes. Green Infrastructure (GI) offers ESS as complementary service to engineering Infrastructure. Its potential as an urban risk mitigation tool is attracting urban authorities to use it as a resiliency tool. The Green Resilient Infrastructure (GRI) can help towards social, economic and environmental sustainability with the additional advantage of mitigation. Urban water management through GRI can resolve problemslike flooding, water scarcity and other associated problems like urban heat island (UHI), pollution, etc. India's urban growth rate is unprecedented now and cannot offer quality living standards; there is an opportunity to make substantial improvement to this deteriorating urban climate using GRIs. The paper reviews the issue further into policy and refers to two Asian initiatives. In Kyoto City, successive landscape policy formulation and implementation has helped the city to preserve water as an essential urban element, and to mark celebrations with its pristine rivers. The city is now equated with most sought-after urban living quarternestled within nature; and visibility of urban waters add beauty and safety both. China's sponge city mission is another case where struggling cities are relying on water-based GIs to convert them into GRIs to survive and celebrate urban lives. Both these cases are learning lesson for emerging countries like India and every city has a future with water to celebrate and manage risks.

Keywords: urban water, celebration, ecosystem services, green infrastructure, urban risk, green resilient infrastructure, Kyoto, sponge city.
\end{abstract}

\section{INTRODUCTION}

Urban Infrastructure offer quality urban living for mass population and are critical components of modern civic functions. Engineered public infrastructure comprise of network of roads, pipes, systems and facilities, and data to serve people with goods and services. These infrastructure require major capital to build and maintain, and occupy large land, a scarce urban resource [1]; they are referred as grey infrastructure [2], and are single purposebuilt and provide limited connect between people and nature. Green Infrastructure (GI), alternative or complementary to grey infrastructure, accommodates nature and its ecological process to provide service.

Urban India's fast-growing economy is attracting people resulting in extensive urban sprawl and densification [3]. Indian population is expected to reach 472 million in 2020 and 611 million in 2030, compared to 325 million in 2005. This unprecedented development is depleting natural resources within and at periphery of urban growth centres, and inviting increasing urban risk, be it socio-economic health, or urban climate and others. To accommodate burgeoning population, construction industry is growing at a parallel rate contributing an average $6.5 \%$ to India's GDP, and almost $70 \%$ of the buildings that will exist in India in 2030 have not been built yet [4].

There is an urgent necessity to explore methods to intervene with feasible options to improve deteriorating urban climate. Water-based GI,be it river, lake, pond, stream or 
fountain, presents a unique opportunity to change sustainably. The article presents one such exemplary concept which advocates "Celebration ofthe Urban Water" while creating and nurturing water-based, networked GI to integrate ecological processes and enhancing visibility of waterin urban spaces to provide Eco-system services (ESS). Further it explains the dimension of Green Resilient Infrastructure (GRI), a multi-functional urban resiliency tool, for larger recognition. The objectives of the article is to establish the idea that citiesshall celebrate water while conserving nature to accommodate ecological process in addition to urban risk mitigation. Water-centric urban development of Kyoto city, Japan and mission for 'Sponge cities' of Chinaare shared to highlight the importance of planning and policy decision to abate water risk. This shall provide futuredevelopment perspective of Indian cities and towns for future.

\section{URBAN WATER CELEBRATION}

Water in urban areas is underperforming due to modified hydrological cycle where rainwater falling on impermeable surfaces runoff quickly from city premise through storm water drainage system. Limited interception of storm water happens through evaporation by solar radiation from water bodies, soil and plants into the atmosphere. Quantitative depletion and qualitative degradation of water in cities and towns presents seriousseasonal consequences of flooding and drought; water imbalance gives rise to thermal discomfort, pollution and lesser visibility of water in urban fabric. Water, left by design or by default within urban areas, deliver multiple social, economic and environmental values and services to communities: livelihood, wisdom, culture, entertainment, sensibility, and most importantly nature connect. Water-based GIs play significant role in changing urban climate. Through integration of natural processes in network of green places and water systems (Green and Blue), water-based GI provides facilities and spaces for social connections boosting longterm economy, and local job opportunities [5]-[7]. Urban water management can render urban risk resiliency service in addition to triple bottom line services from perspectives of the provider (city or neighbourhood authority) and the consumer (local residents, tourists).

River and creek corridors, waterways and wetlands, canals, fountains, ponds etc. can be employed as tangible water-based GI. Gardens, squares and plazas with permeable cover and vegetation, green area, sports field and cemeteries, public parks, urban forest reserves, agriculture farms and orchards, permeable promenade, large scale utility areas including quarries and airports, remnant patches of natural vegetation and unused land are urban water reserve; they control thermal comfort, water quality and availability for future, and pollution. They are assetsto be preserved or conserved which are not duly recognised while developing urban areas.

Water historically facilitated cities to survive, sustain, celebrate and create distinguished identities; experiences of water element in early civilizations are inspiration as a component of urban design for present and new towns. Tigris-Euphrates, Nile, Tiber provided numerous urban centres through ages. Indian urban experience of celebrationin association with water is very long, enriching and well-experimented. Cities on the bank of river Indus, Ganges or others flourished through different times of history; citizens develop and maintain water based GI, experience and celebrate watertill date. Come evening, ghats are the activity places for many of these riverside towns till date. Within temples water is preserved within tanks and its sanctity has always been tended as priority. Cities from water-stressed region, bear expressions of water conservation as an integral urban identity. Cities celebrating water while conserving nature to accommodate ecological process to mitigate urban risk are evident from Fig. 1. 


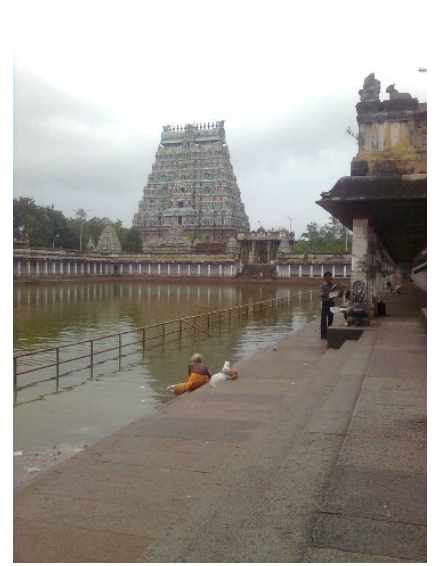

(a) Temple Tank in Chennai

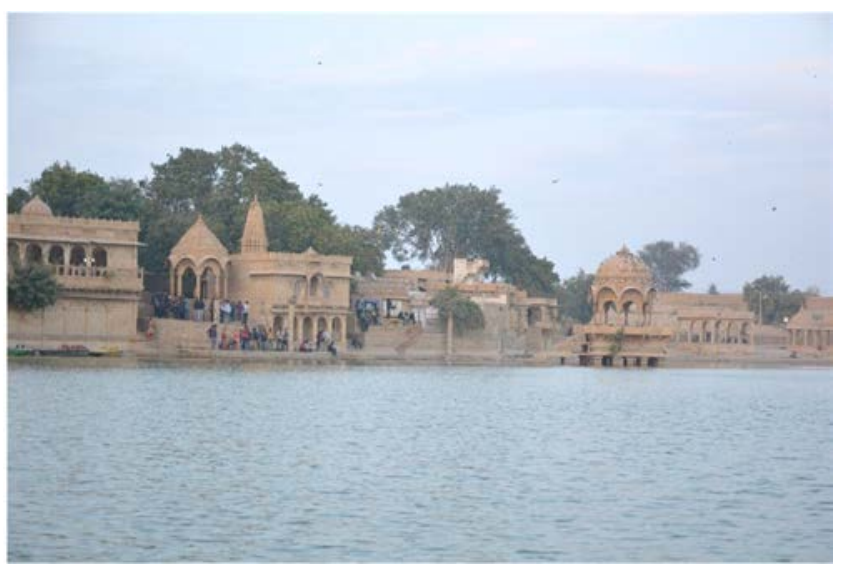

(b) Urban Lake in Jaiselmer, Rajasthan

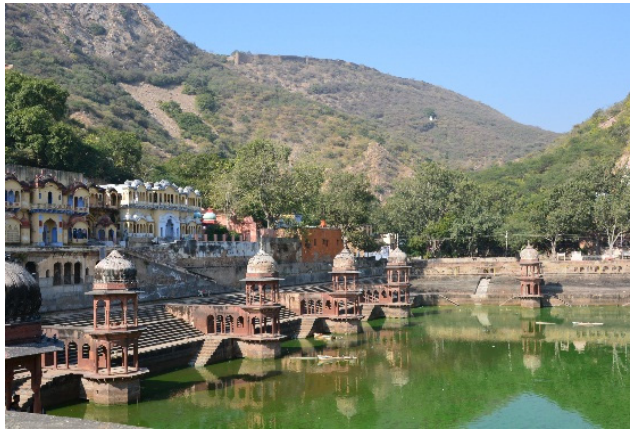

(c) Rain water-fed Urban Lake in Alwar

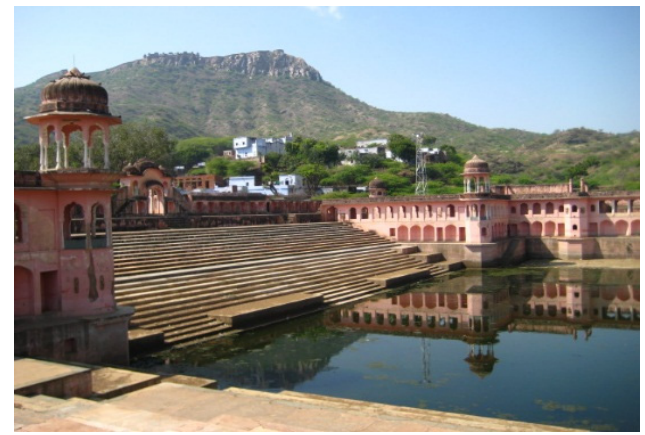

(d) Early example of GI in Khetri, Rajasthan

Figure 1: Urban water and its celebrations in Indian Towns and cities.

Water, traditionally, offers cultural and heritage value, attachment and symbolism to space and users; thus augmentsidentity, comfort, safety, security for water and food, and community liveability. This benefits society by offering opportunities for recreation, aesthetic, physical and psychological wellbeing, social interaction, and education [9]. Water doubles up as mode of function like transportation and source of recreation. Sensory appreciation of trickling water help in therapeutic healing through emotional relaxation; landscaped areas offer attractive place-making, walkability and physical activity space which help in reducing stress and doctor visit [10]. Psychological health and wellbeing gets rejuvenated with positive emotions with nature connect and helps in stronger social interaction boosting sense of identity and community building. Knowledge offered by water about nature and processes, and aptitudes are fascinatingly important human life-skills for children and adults alike. Physical, intellectual, emotional, and social capacity for children and adolescents are best served by GIs. Water contributes to urban environment quality through rain, flow, evaporation, permeation and storage; and results in access to water, reduced energy use and healthy society. Water-based GI can offer notable resiliency services to urban areas and connectivity ensuring flow through less fragmented habitat [11]. 


\section{URBAN RISKS}

\subsection{Urban risk}

Imbalanced and modified resource cycle brings risks to urban areas; e.g. non/availability of urban water in different season triggers direct flood and drought and associated risks like UHI, pollution etc. In recent times flood risks are in rise in urban areas as vulnerability and exposure increased manifolds [12]. Climate change impact on coastal cities of developing countries is making them vulnerable to urban flooding as intense rainfall and/or storm-surge have increased in recent time [13]. The same cities are experiencing distinct water crisis in summer. Flow of energy and water is hindered and hydrologic cycle is altered in urban process due to increased impermeable surfaces.

Common issues these burgeoning cities confront include urban flooding and drought, Urban Heat Island (UHI), air pollution etc. directly impacting upon citizens' quality of urban living. Water can attenuate all these problems in varying degree. Most of the future Indian cities are yet to be built.India's urban growth rate is unprecedented now and cannot offer quality living standards; there is an opportunity to make substantial improvement to this deteriorating urban climate using GRIs. Urban water management through GRI can resolve problems related to urban water like flooding, water scarcity and associated problems like urban heat island (UHI), pollution etc.

\subsection{Risk assessment}

Urbanization brings fragmented and modified interaction between biotic-abiotic elements through construction and surface transformation. The Sendai Framework advocates risk assessment for risk reduction, which consists of identification, analysis and evaluation of risk (Fig. 2) [14], [15]. Risk identification recognizes hazard type, scale, extent, historic evidence and elements at risk, working group and end users' context. Risk analysis considers risk and consequences through hazard, vulnerability, exposure and coping capacity analysis through mapping, survey techniques, data analysis employing mathematical modeling and simulations. Risk evaluation compares risk analysis resultsto identify range of acceptable or tolerable risk. Increasing urban population puts more lives, assets, infrastructure and habitat to risk, and thus make risk profiling very important.

Flooding ordeals are common to small towns as well as large dense metropolises and most recent floods in London and Paris in 2016 are example for the same. Heavy rainfall is one major cause for urban flooding in India. Old and insufficient drainage systems get blocked by silting, dumping of waste material through inlets and encroachment; and fail to drain efficiently [16]. Poor people living next to risk prone areas like river flood plain, natural or sewage drainage channels, are vulnerable to flooding and water scarcity both. With very limited purchasing capacity they are bound to buy water for drinking and other purposes.

The associated urban climate risks like UHI get aggravated in absence of moisture in the ambient environment. Attenuation of UHI phenomena using urban water is an established strategy as it adds moisture to urban climate. Efficiency of GRIs can be estimated using software simulation tools like SWMM, i-tree. Scalenghe and Marsan [17] report use of storm water models to evaluate risk scenario of integrating GI, low impact development (LID) in Boston, USA and predicted possible attenuation impacts. 


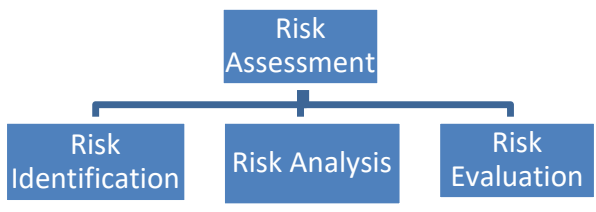

Figure 2: Risk assessment.

\section{URBAN WATER AS GRI}

Urban climate modifications like sealing of surfaces, construction of buildings and other structures and anthropogenic interventions bring serious consequences like risks of UHI, flooding etc. Urban water based GI can be a key tool to improve deteriorating urban quality of life [18]; this can be employed as a GRI, in which engineering solutions integrating natural processes will manage storm-water drainage through soil infiltration and storage, flow control and flood reduction, and canopy interception. Permeable surfaces and GI components like bioswale, rain garden, retention and detention tanks, and pavement corridors can maintain urban water ecosystem, can be source of urban celebration as well as can provide resiliency.

\subsection{Urban flood attenuation}

Structural connectivity of GI components physically, or functionally ensures natural and ecological processes, and thus can be resiliency measure to urban flooding. Function of natural processes of heat, water, carbon, and nitrogen cycle is difficult to ascertain in numbers [19]. Urban flood risk analysis builds up on historical data on frequency, intensity and consequences; data efficiency is pre requisite to make dependable risk assessment. This can be analyzed using data-based model analysis. Instead of political decision, choice of development decisions shall be offered based on risk-based analysis.

Integrated risk based assessment of urban flooding considers technical issues like spatially varying rainfall, space making strategy for water, reduction in impervious cover etc. [11], [19], [20]. Zhang et al. [22] estimated runoff reduction and rainwater storage potential in Beijing using active green area. Davey Resource Group [23] evaluated storm-water interception function and value of street tree population in Pittsburgh, USA. Role of inland and coastal wetland in flood protection are reported by Morris and Camino [24]. Efficiency of green roofs to retain varying amount of rainfall of up to $100 \%$ depends on depth of the substrate cover, slope and vegetation type of the roof. Similarly, Kazemi et al. [25] reported competence of bio swales on storm water retention in Australia. Rainwater harvesting using rain gardens act as modifier in risk-based land-use planning, as part of urban flood mitigation process. In the backdrop of engineered infrastructure's limited performanceand rapid urban growth in India, GRI is aninsightful alternative to offer new avenues to mitigate adverse urban climate in addition to visibility of water in urban-scape.

\subsection{Urban heat island mitigation}

Influences of urbanization on urban climate are many; UHI being most significant one as it impacts on human health, productivity and energy consumption directly. Re/development 
plan of urban neighborhoods considering water components, their size, location, orientation, connectivity etc. can helpUHImitigation and Storm-water management immensely. Land use land cover (LULC) play significant role in urban microclimate management. In addition to surface albedo, vegetation, wind, water/ moisture are crucial to control UHI intensity. Oke [26] marked cloud cover and wind speed affects UHI; and Morris et al. [27] estimated the impact as (cloud cover + wind speed affects) ${ }^{0.25}$. Cooling effect of water ranges between 1 and $3^{\circ} \mathrm{C}$ up to $30-35 \mathrm{~m}$ distance. Cooling capacity of $4 \times 4 \mathrm{~m}$ pond is reported as $1^{\circ} \mathrm{C}$ up to $30 \mathrm{~m}$. It's most active during 14.00 to $15.00 \mathrm{hrs}$ (temporal). Any full-grown tree uses $20-30 \mathrm{kw}$ of solar energy for evapotranspiration as latent heat and this is equivalent to $10 \mathrm{AC}$ units. If tree cover can be increased from $45 \%$ to $60 \%$, net blackbody radiation flux reduction is $14 \% .100-1000 \mathrm{~m}^{2}$ vegetated area cools 1 to $4.7^{\circ} \mathrm{C}$. Small, distributed vegetated area spread throughout an area extend the thermal benefit of vegetation beyond the physical boundary more effectively than a large, continuous vegetated area of same size in a central location [28], and Shashua-Bar and Hoffman [29] reported perceivable cooling effect $100 \mathrm{~m}$ from small green site.

Thus, urban scientists established multiple benefits of mitigation through GRIs, as same water based GRI can control UHI, storm water to attenuate flooding and drought scenario, and pollution, yet add beauty and spaces to urban areas for celebration in outdoor. Despite being so potential tool, GRI integration into urban development is not easy; through policy development and rigorous implementation of the same can ensure success.

\section{WATER-CENTRIC URBAN DEVELOPMENT}

Some of the appreciable urban development took water as an urban element seriously; development while conserving nature including water, help to accommodate ecological process as well as urban risk mitigation.Corrective measures centred on water based strategy are quite common too, especially when the cities face crisis and need to change the course of actions. To illustrate the point further two cases will be presented in following section. Appropriate policy development with time and its rigorous implementation has protected Kyoto City's innate connect with nature, and one can find how water takes the central stage in the city. 'Sponge cities' are an ensuing attempt to improve urban living quality in China employing natural process to curb pollution risk. The first one assures the improvement benchmark can be of unbelievable quality, whereas the second seconds that every city has a future with water to celebrate and manage risks.

\subsection{Kyoto city and water}

Kyoto, the earlier capital of Japan, exhibits one of the best urban water management example with profound maturity; this is an inspiring learning model with regard to urban living quality. Insightful management of natural resources of Kyoto city has evolved with time. Kyoto Landscape's prime attention is to maintain/ enhance aesthetics and heritage value [30]. Water-side natural open-spaces, essentially maintained for natural eco-processes and to hold additional storm water to avoid urban flooding, are providing recreational spaces for the citizens. In case of earthquake, the riversides can be used as evacuation places too.

Kyoto has rivers and waterways of varied sizes blended with greeneries, and they create attractive panorama of "Views of waterfronts". Kamo and Katsura riverbanks serve as precious spots for viewing the surroundingmountain ranges. Waterside development brought distinct social gatherings, celebration of Kyoto lives, and economic activities aside river corridors; cultural and religious celebrations of the city is deeply connected to it. Landscape planning of the city is important urban governance issuefor decades; mountain and rivers are 
key landscape elements. This is very interesting to understand the successive administrative decisions helped to conserve natural heritage of the Kyoto with continuously raising the bar to reach at its present form. An historical account is provided below.

Japan adopted municipality system for Kyoto led by national government in 1889 and in 1898 autonomous city government was established and started with the concept ofpreservation of the scenic beauty and noteworthy sights and historical scenery without compromise. The City Planning Act and the Urban Building Law were enacted in 1919 which enforced regulations concerning zones and districts, building height and structure. The Scenic Landscape District designation of 1930 covered area-level preservation of Historic, Scenic and Natural Monuments and neighborhoods.
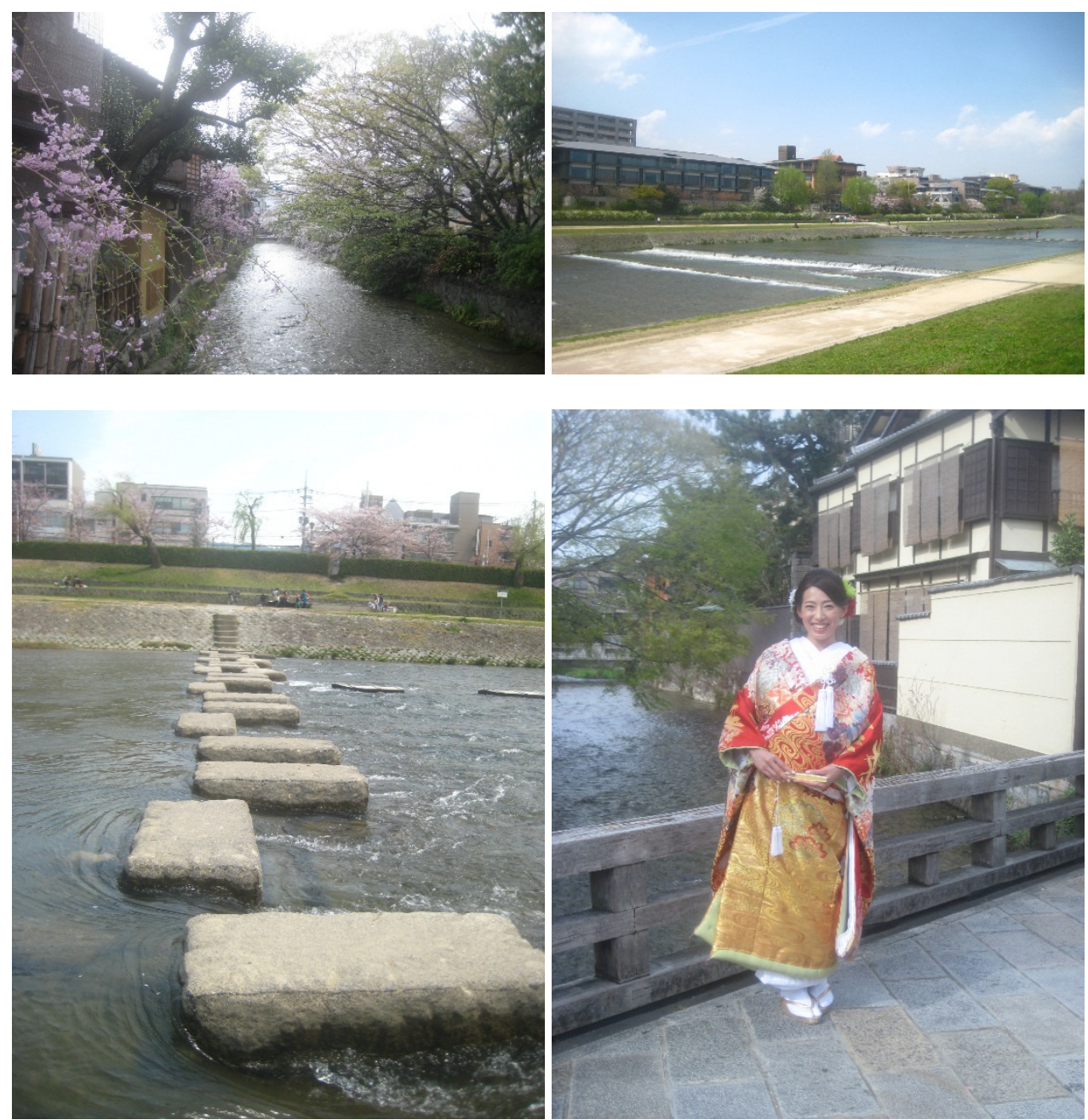

Figure 3: Lives around water in Kyoto. 
The Law for Kyoto International Culture and Tourism City introduced Green Zones in 1950, and allowed Kyoto to conserve natural landscape by the strict regulation of buildingto-land ratio in the Green Zone. In 1956, administrative authority for the scenic landscape was transferred to Kyoto city from Kyoto prefecture. The Ancient Capitals Preservation Law enforced in 1966 was an epoch-making landscape policy in Japan which designated historical areas as the Historical Climate Special Preservation District. Land development was banned to protect historic sites and beauty spots which stood with the natural environment surrounding them. The first long-term plan after the war "Vision of the Development of Kyoto in the coming 20 Years", launched in 1969, advocated balance between conservation and development. The areas along the mountains and rivers were designated as Landscape Conservation Area to improve the urban landscape that copes with the demand of new urban functions. The entire city was designated as Landscape Development Area.

In 1988, the city formulated the "Guideline for Comprehensive Design System" which allows to alleviate the limitation of the building height and to increase floor-area ratio by offering public space in the building site. Signage received due attention. The "Council for Kyoto City Development on Measures for Land Use and Landscape" was set up to draw the basic guideline in 1991. In 1995, "Ordinance for the Conservation of Natural Landscape" and amended Urban Landscape ordinance renamed as "Kyoto City Ordinance on Development of Urban Landscape" were enacted to preserve the natural and urban landscape before war and to pass them down to the future generations. Kyoto city waterside natural open-spaces are mandatory; this helps for providing natural amenities as well as space for evacuation in case of urban disaster. Lost watersides are recreated and reactivated in order to improve resiliency of the city [31].

The Ministry of Land, Infrastructure, Transport and Tourism enforced the Landscape Act in June 2005 to promote an excellent landscape and comfortable living environment in communities in partnership with citizens, enterprises and government. The New Landscape Policy was established in September 2007 to extend comprehensive support system including financial support. Riverside types of Aesthetic districts are identified where buildings are blended with attractive water space. Where development is less, an elegant riverside landscape will define Aesthetic Formation district, which will be in harmony with the attractive waterfront area and the mountains at the background.

Continuous evolving policies helped Kyoto to retain the most beautiful world city tag on her and be a leading example for other urban centers of the world.

\subsection{Sponge cities of China}

China, is facing worst crisis in its urban history, perhaps, due to rapid industrial urbanization, pollution and poor urban facilities for transportation, water and waste management. Many Chinese cities are considered severely water scarce by UN measures, and fail to reach national standards for flood prevention. Older urban areas do not have basic flood prevention measures. In 2013 several Chinese cities were affected by flooding. As a measure, 16 urban districts across the country are identified to become pilot sponge cities. These cities will receive funding support with a target to manage $60 \%$ of rainwater falling in the cities through developing ponds, filtration pools and wetlands, permeable roads and public spaces that enable stormwater to soak into the ground. Floodplain and wetland protection, restoration of green spaces along rivers, intelligent network planning of urban green spaces are being introduced in these 16 urban districts to reduce flood risks and to manage water resources. A sponge city absorbs, harvests, stores, filters, purifies, and slowly releases rainwater - like a sponge. Natural hydrological cycle, i.e. rainwater retained, naturally filtered, cleaned and 
conveyed, and then slowly drained into the soil for groundwater recharge and/or discharged into rivers -is the principle of the sponge city. Such cities can harvest rainwater for farming and landscape irrigation in water scarce regions and in light of increasing pollution and competing demands for water, the strategy can contribute to water security, a target identified in SDG 6 and a key global and regional challenge of Asia. Sponge cities will reduce carbon emissions and help fight climate change in long run.

An array of linked GIs such as preserved floodplains, storm-water wetlands, retention ponds, sunken parks, seepage wells, and green roofscan help these cities to achieve the sponge city target. Initiative starts from domestic rainwater harvesting with rooftop gardens. This in turn reduces run off as well as tropical air temperature, reducing the energy needed to cool the building. At ground level, impervious concrete can be replaced by bioswales, ditches filled with native plants that naturally collect and filter rainwater; that water can then either be allowed to seep into the soil to replenish the groundwater or be collected in underground cisterns or irrigate gardens and urban farms. With cities getting bigger and climate change threatening to bring more extreme weather, by connecting multiple water related ecosystems services, a sponge city can attenuate impact of urbanization on the natural water cycle. An urban reimagination, a sponge city, where almost every raindrop is captured, controlled and reused instead of funneling away, uses rainwater within its own boundaries.

A cluster of buildings at University of Hong Kong installed with rooftop gardens are an experiment to monitor whether trapped rainwater can replace half of all the toilet water they use. Singapore is processing it to drink.

\section{CONCLUSION}

Urban risks are looming large and risk management now starts with risk reduction. Water being important component of urban design, can continue to be source of inspiration and celebration. This can be an opportunity and a resource to augment our resource reserve provided urban water is considered for GRI, and not as a problem. The Kyoto city example convinces one that efficient implementation can help benchmark to be shifted continuously to achieve unbelievable quality of water management where water is the source for urban celebration as well as multi-hazard resiliency tool. The sponge city concept assures that every city has a future with water to celebrate and manage risks.

\section{REFERENCES}

[1] Wolf, K.L., Ergonomics of the city: Green infrastructure and social benefits. Proceedings of the $11^{\text {th }}$ National Urban Forest Conference, ed. C. Kollin, Engineering Green, American Forests: Washington, DC, pp. 141-143, 2003.

[2] McKenna, D., Task 4.1 In-depth case analysis-Green Infrastructure Implementation and Efficiency - Theme 6: Grey Infrastructure Mitigation. Report for the European Commission, Institute for European Environmental Policy, IEEP: London, DG Environment on Contract ENV.B.2/SER/2010/0059, 2011. Online, www.ieep.eu/ assets/898/Green_Infrastructure Implementation_and Efficiency.pdf. Accessed on: 17 May 2016.

[3] McKinsey Global Institute (MGI), India's urban awakening: Building inclusive cities, sustaining economic growth, April 2010.

[4] JLLM, Accelerating Transformation: Investments in Indian Real estate, Knowledge Centre-White paper series volume 2:2, Jones Lang Lasalle Meghraj, 2007. Online, https://www.scribd.com/document/135337800/Accelerated-Transformation.

Accessed on: 21 Apr. 2017. 
[5] Jim, C.Y. \& Chen, W.Y., Perception and attitude of residents toward urban green spaces in Guangzhou (China). Environmental Management, 38(3), pp. 338-349, 2006.

[6] Naumann, S., McKenna, D., Timo, K., Mav, P. \& Matt, R., Design, implementation and cost elements of Green Infrastructure projects. Final report to the European Commission, DG Environment Contract no. 070307/2010/577182/ETU/F.1. Ecologic Institute and GHK Consulting, 2011.

[7] Tzoulas, K., Korpela, K., Venn, S., Ylipelkonen, V., Kaźmierczak A., Niemela, J. \& James, P., Promoting ecosystem and human health in urban areas using green infrastructure: A literature review. Landscape and Urban Planning, 81(3), pp. 167178, 2007.

[8] Zhou, X. \& Rana, M.M.P., Social benefits of urban green space: A conceptual framework of valuation and accessibility measurements. Management of Environmental Quality, 23(2), pp. 173-189, 2012.

[9] Ely, M. \& Pitman, S., Green Infrastructure - Life support for human habitats: The compelling evidence for incorporating nature into urban environments, Botanic Gardens of Adelaide, Department of Environment, Water and Natural Resources: Adelaide, 2014.

[10] Kato, S., Green infrastructure for Asian cities: The spatial concepts and planning strategies. Journal of the 2011 International Symposium on City Planning, Korea Planners Association, pp. 161-170, 2011.

[11] Jha, A.K., Bloch, R. \& Lamond, J., Cities and Flooding: A Guide to Integrated Urban Flood Risk Management for the 21st Century, International Bank for Reconstruction and Development: Washington, DC, 27, 2012.

[12] IPCC, Climate Change 2007: Synthesis Report, IPCC: Geneva, Switzerland, 2007.

[13] UNISDR, UNISDR Terminology on Disaster Risk Reduction. UNISDR, 26, 2009.

[14] SEERISK Consortium, Guideline on Climate Change Adaptation and Risk Assessment in the Danube Macro-Region, University of Vienna, and National Directorate General for Disaster Management, 106, 2014.

[15] De, U.S., Singh, G.P. \& Rase, D.M., Urban flooding in recent decades in four mega cities of India. Journal of Indian Geophysical Union, 17(2), pp. 153-165, 2013.

[16] Pyke, C., Warren, M.P. \& Johnson, T., Assessment of low impact development for managing stormwater with changing precipitation due to climate change. Landscape and Urban Planning, 103, pp. 166-173, 2011.

[17] Scalenghe, R. \& Marsan, F.A., The anthropogenic sealing of soils in urban areas. Landscape and Urban Planning, 90(1-2), pp. 1-10, 2009.

[18] European Commission, The multi-functionality of green Infrastructure, 2012. Online, ec.europa.eu/environment/nature/ecosystems/docs/Green_Infrastructure.pdf.

Accessed on: 20 Dec. 2015.

[19] Davey Resource Group, i-tree streets and i-tree eco inventories and reports, 2009, http://www.davey.com/cms/resource library/files/a0efb4322e3f6802/index.html.

Accessed on: 3 Jun. 2016.

[20] DEFRA, Biodiversity 2020: A strategy for England's wildlife and ecosystem services, 2011. Online, https:/www.gov.uk/government/uploads/system/uploads/attachment data/file /69446/pb13583-biodiversity-strategy- 2020-111111.pdf. Accessed on: 12 Apr. 2016.

[21] Kellagher, R.B.B., Sayers, P.B. \& Counsell, C., Developing a risk-based approach to urban flood analysis. 11th International Conference on Urban Drainage, 31 August5 September 2008, Edinburgh, UK. Online, https://web.sbe.hw.ac.uk /staffprofiles/ 
bdgsa/11th_International_Conference_on_Urban_Drainage_CD/ICUD08/pdfs/249.p df. Accessed on: 11 Jun. 2016.

[22] Zhang, B., Xie, G., Zhang, C. \& Zhang, J., The economic benefits of rainwater-runoff reduction by urban green spaces: A case study in Beijing, China. Journal of Environment Management, 100, pp. 65-71, 2012.

[23] Davey Resource Group, i-tree streets and i-tree eco inventories and reports, 2009. http://www.davey.com/cms/resource library/files/a0efb4322e3f6802/index.html. Accessed on: 3 Jun. 2016.

[24] Morris, J. \& Camino, M., Economic Assessment of Freshwater, Wetland and Floodplain Ecosystem Services, UK National Ecosystem Assessment, Cranfield University: Cranfield, 2010.

[25] Kazemi, F., Beecham, S. \& Gibbs, J., Streetscape biodiversity and the role of bioretention swales in an Australian urban environment. Landscape and Urban Planning, 101, pp. 139-148, 2011.

[26] Oke, T.R., Boundary Layer Climates (2nd ed.), Routledge: Cambridge, 1987.

[27] Morris, C.J.G., Simmonds, I. \& Plummer, N., Quantification of the influences ofwind and cloud on the nocturnal urban heat island of a large city. J. Appl. Meteor, 40(2), pp. 169-182, 2001.

[28] Honjo, T. \& Takakura, T., Simulation of thermal effects of urban green areas on their surrounding areas. Energy and Buildings, 15-16, pp. 433-446, 1991.

[29] Shashua-Bar, L. \& Hoffman, M.E., Vegetation as a climatic component in the design of an urban street: An empirical model for predicting the cooling effect of urban green areas with trees. Energy and Buildings, 31(3), pp. 221-235, 2000.

[30] Kyoto City Web, Online, http://www.city.kyoto.lg.jp/tokei/page/0000057538.html. Accessed on: 20 Jan. 2017.

[31] Hatayama, M. \& Hagihara, Y., Change in Disaster Prevention Function caused by Regeneration of Water side and a Proposal for Restructuring Regional Community as an implementation scape in an Urban Area, Kyoto. 